A joint project of the College Center for Library Automation and the Tampa Bay Library Consortium has been awarded a $\$ 339,000$ Library Services and Technology Act grant. The grant will provide for the collaborative development and delivery of live virtual online reference services to more than 4 million library patrons throughout Florida.

\section{UCLA's Department of Information}

Studies is one of seven recipients of a grant from the Institute of Museum and Library Services. The grant will fund a one-year project training eight professional librarians in research, information technology, and policy to prepare them for future doctoral studies. It will also award participants a post-MLS certificate and will assist them in preparing study plans for doctoral programs.

\section{SOLINET's Preservation Services has}

been awarded two grants from the National Endowment for the Humanities. A $\$ 580,000$ grant will go to continued support of Preservation Field Services. Highlights of the two-year project will be one- and two-day workshops on preservation topics; a conference on preservation concerns during building and renovation projects; expanded consulting services; and the Web publication (in English andSpanish) of Hurricane! Surviving the Big One: APrimerforLibraries, Museums, and Archives.A $\$ 700,000$ grant will support the sixth cooperative preservation microfilming project. This two-year project will preserve 6,000 brittle volumes from 16 participating institutions; the volumesfocus on U.S. Southem history and culture.

\section{The University of Pittsburgh's University}

Library System (ULS) has received a two-year National Leadership Grant of $\$ 242,157$ from the Institute of Museum and Library Services to digitize more than 7,000 photographs depicting Pittsburgh's immigrant workforce, steel industries, public schools, civic renaissance of the mid-1940s and 1950s, and African American communities. The images will be availableon the ULS Historic Pittsburgh Web site at http:// digital.library.pitt.edu/pittsburgh/.
The New York State Historical Association (NYSHA) has received a $\$ 40,000$ grant from the Gladys Krieble Delmas Foundation's Research Library Program to develop an online library system to improve access to the NYSHA research library's collections. NYSHA's research library has developed important collections on American and New York State history and culture, American art history, Native American art and culture, folklore, and museum studies.

\section{The University of Illinois at Urbana-} Champaign Library has been awarded a \$1 million grant from the Andrew W. Mellon Foundation to increase scholarly access to its outstanding collections and rare book materials. The grant provides funds for retrospective conversion, a process through which computerized records will be created or expanded for library materials. The two categories of items targeted are the 1.6 million records in the Online Library Catalog that lack complete bibliographic information (primarily accessed by subject headings) and the approximately 16,000 volumes of rare books that are not contained in the Online Library Catalog (accessible only in paper format).

\section{The Northeastern University (Boston)}

Libraries were awarded $\$ 21,479$ to pursue special projects that will better serve library patrons. The Media Center's Serving People with Disabilities award of $\$ 19,979$ will improve access to library information resources, remove barriers that impeded access, increase awareness about library services for people with disabilities, and expand training to staff and patrons with disabilities. The Archives and Special Collections Department's preservation survey grant of $\$ 1,500$ will provide funding to hire a consultant to survey the archives collections and facility.

\section{Cornell University Library has received} a $\$ 725,088$ grant from the National Science

Ed. note: Send your news to: Grants \& Acquisitions, C\&RL News, 50 E. Huron St., Chicago, IL 60611-2795; email:agalloway@ala.org. 
Foundation to create a digital collection of historical machine models for the National Science Digital Library. This new online collection will provide educators, students, researchers, and the general public with tools for exploring the mathematical motions of machines. The collection will be geared for use by middle school, high school, and college-level teachers.

\section{Acquisitions}

\section{The papers of Arthur Levitt Jr. , chairman}

of the U.S. Securities and Exchange Commission (SEC) from 1993 to 2001, have been arranged and described by Columbia University's Rare Book and Manuscript Library. The library will add 13 boxes of new materials (spanning the years 1993 to 2000) to the existing collection. These new materials contain files regarding significant cases and events during Levitt's SEC tenure, materials on auditors' independence and market regulation, and a collection of original news clippings, photos, and correspondence.

The Alice P. Green Papers, which constitute the writings, career, activities, and history of events in the life of this political activist in New York State, have been acquired by the University at Albany. Green's most acclaimed work has been done in the criminal justice area, where she has worked tirelessly to promote prison reform and advocate on behalf of prisoners. The collection, which comprises 3.5 cubic feet of materials, follows Green's career as a criminologist from her days as a graduate student in criminal justice at the University at Albany through her career as founder and current executive director for the Center for Law and Justice in Albany.

The historiclibrary shelving system that was housed in the former ASPCA Building at 50 Madison Avenue in New York City has been donated to the Wolfsonian at Florida International University by Samson Management. Samson is renovating the 1896 limestone edifice in which the shelves were housed into condominiums. The shelves, which were the first modular book-stacking system ever created, were designed by Angus Snead Macdonald (1883-1961) and built from iron by Snead and Company Iron Works. Their design was avant-garde, as they provided fireproofing protection and ventilation for the books.

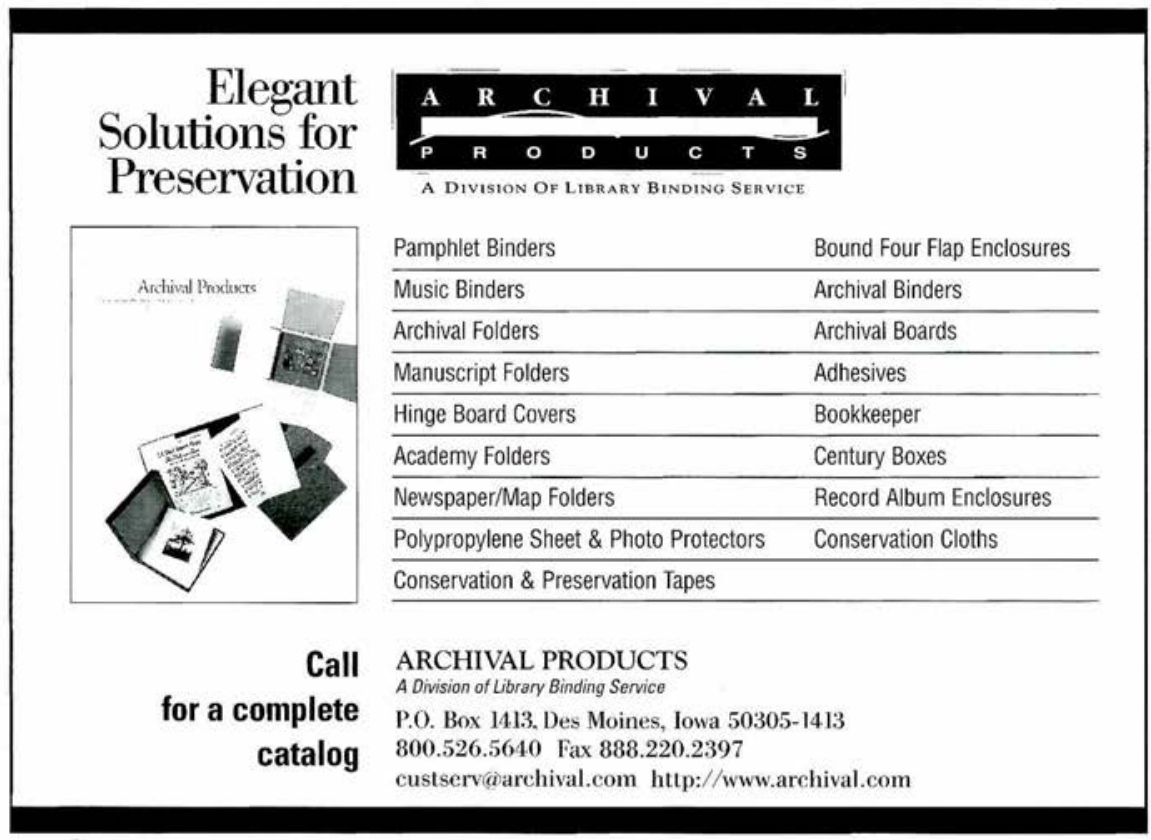




\section{Get ahead, \\ take control.}

Swets Blackwell is there to help you take control of the complex and time-consuming processes involved in managing electronic content. From rapid set-up of electronic subscriptions to full integration with library management and e-procurement systems and advanced article delivery solutions, we can help.

Our sophisticated aggregator service enables speedy delivery of several thousand e-titles from a multitude of prestigious publishers right to your desktop. Want to learn more?

Visit us at www.swetsblackwell.com/ejs

www.swetsblackwell.com

160 Ninth Avenue, P.O. Box 1459 Runnemede, NJ 08078

T: 800-645-6595 • F: 856-312-2000

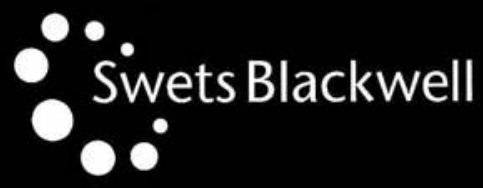

